\title{
A Representação Social da Maternidade de Crianças em Idade Escolar
}

The social representation of motherhood in school-age children
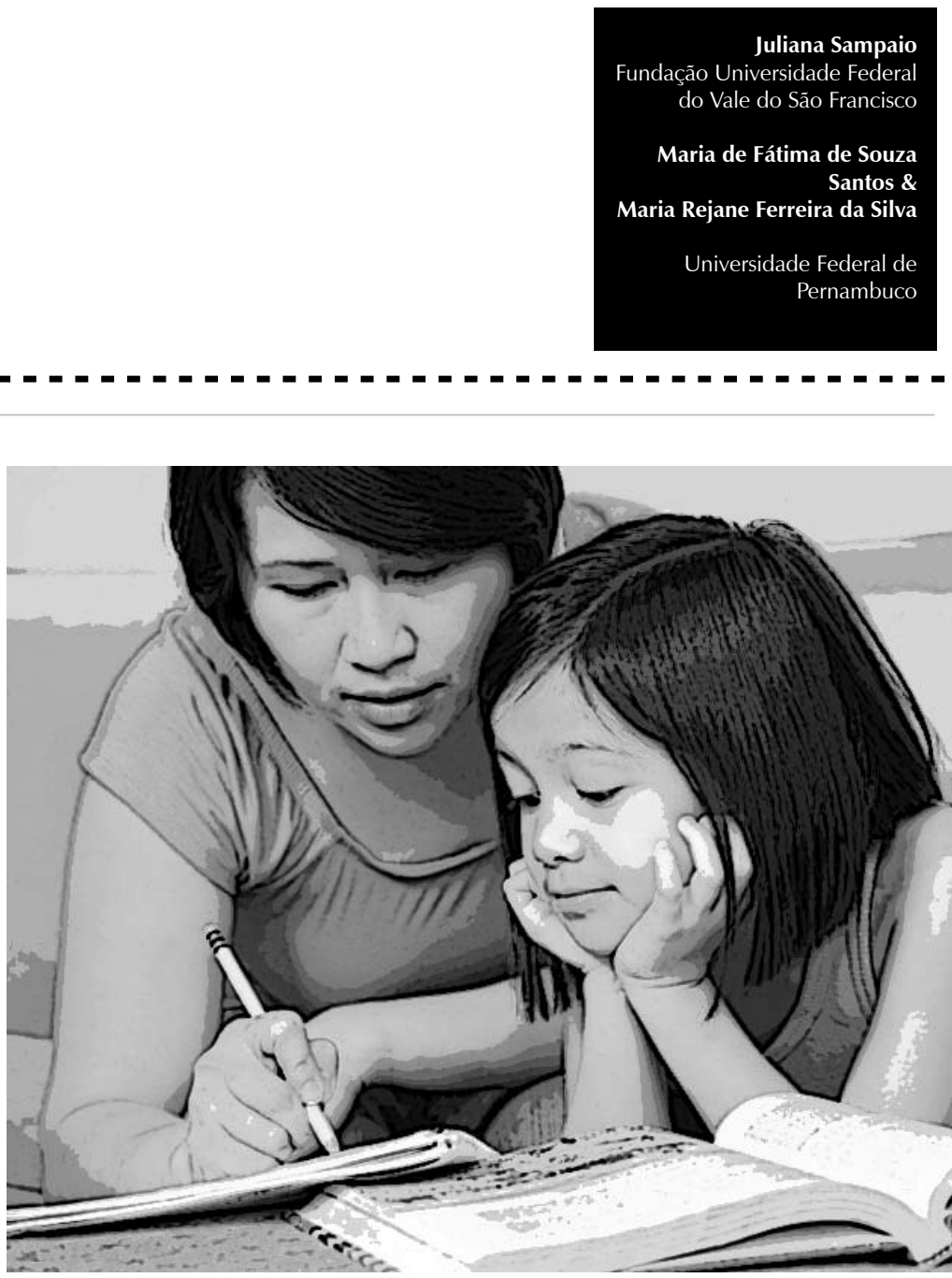
Resumo: As representações sociais são conhecimentos socialmente articulados que dão sentido à realidade. A criança, ao se apropriar da realidade, compartilha significados, dá sentido à figura materna e, em conseqüência, ao seu próprio papel de filho/a. Este estudo investiga o conteúdo e a estrutura da representação social da maternidade de crianças em idade escolar de classe social média-alta. Foram aplicadas entrevistas semidirigidas, solicitados desenho e história sobre mãe e aplicado o teste de tri-hierarquização de itens, de Abric (1994), para 16 crianças de ambos os sexos, entre 8 e 10 anos, de uma escola particular do Recife. Observou-se que a representação social de mãe está calcada no amor e abnegação incondicionais ao filho, que respaldam tarefas como dar limites, educar, passear, dar carinho. Conclui-se que o amor e a abnegação são o núcleo central da representação da maternidade e têm conseqüências diretas na estruturação da identidade de crianças e mulheres.

Palavras-chave: Representação social. Maternidade. Crianças em idade escolar. Identidade.

\begin{abstract}
The social representations are social articulated knowledge that bring about significance to reality. As the child understands reality, he/she shares meanings and gives sense to the maternal figure and consequently to his or her own social role as son or daughter. This work investigates the content and the structure of the social representation of motherhood of school-age children from upper-middle social classes. Semi-structured interviews were applied, a drawing about motherhood was requested, the children were asked to tell a story and the Abric tri-hierarchic test of items (1994) was applied to 16 children of both sexes, between 8 to 10 years old, from a private school in Recife. The study showed that children share a representation of mother based on unconditional love and self-denial on behalf of her child, what legitimates tasks as setting limits, educating, taking for a walk, giving affection etc. The results showed that love is the core of motherhood representation, what affects directly the identity of women and children.
\end{abstract}

Keywords: Social representation. Motherhood. School age children. Identity.

\title{
A maternidade enquanto objeto socialmente construído
}

A representação social da maternidade é um construto social que orienta as práticas e os afetos dos sujeitos sociais. A partir de noções socialmente construídas do que é ser mãe, são orientadas as relações sociais entre mãe e filho assim como a própria identidade de ser mulher.

O que hoje se considera como um bom referencial de mãe é bastante discordante do que se concebia, por exemplo, na Europa, nos sécs. XVII e XVIII. Alguns comportamentos maternos considerados naquela época normais, corretos e esperados seriam algo anormal, incorreto e incompreensível no contexto de várias sociedades contemporâneas (Azevedo \& Arrais, 2006).

Por isso, a prática materna valorizada deve ser compreendida dentro de um contexto socio-cultural, e não sob a ótica de uma suposta determinação biológica para o desejo e o desempenho da maternidade (Dias \& Lopes, 2003). De outra forma, como entender valores maternos tão diferentes nos diversos momentos da História?

As contribuições de autores como Badinter (1985) e Ariès (1981) permitem a reconstrução da trajetória histórica da significação dos cuidados maternos. Badinter (1985) parte 


\section{Como o maior} índice de

mortalidade se concentrava na época da amamentação, na qual a criança era entregue aos cuidados de uma ama, começou nesse século um grande movimento social, encabeçado pelas instituições de saúde, que visava à construção de um novo papel social para a mãe. das produções simbólicas construídas desde o séc. XIX pelas sociedades européias, mais precisamente a francesa, no seu processo de urbanização, demonstrando como questões de ordem social interferem na construção do que se compreende por amor materno.

O conceito de maternidade está intrinsecamente relacionado com várias representações sociais, dentre elas as de família, mulher e criança. Na Europa, até o século XVII, a infância era considerada um estado a ser superado através de uma educação severa, rígida e intolerante. Cabia aos pais domar os impulsos infantis, assumindo uma posição coercitiva e sem mimos. Por sua vez, a amamentação era vista como um prazer ilícito que corrompia moralmente o infante (Ariès, 1981; Badinter, 1985).

Segundo Ariès (1981), na França, até o séc. XVII, mais acentuadamente no séc. XV, a criança deveria ser educada na casa de outrem como um aprendiz, cabendo-lhe as atividades domésticas, ocasião em que aprendia a "servir bem" aos demais. No final do séc. XVII, começa a surgir para os rapazes mais abastados a opção das academias, onde recebiam estudo teórico, erudito, mas, para as meninas, essa opção só se tornou realidade um século depois. É nesse período que começam os cuidados com a educação formal das crianças e a preocupação com seus afetos. Os filhos mais novos ganham maior atenção dos pais, que até então era destinada apenas ao primogênito (Ariès, 1981).

Badinter (1985) apresenta como um motivo para essa aproximação da criança com o seio familiar a alta taxa de mortalidade infantil no final do séc. XVIII. Como o maior índice de mortalidade se concentrava na época da amamentação, na qual a criança era entregue aos cuidados de uma ama, começou nesse século um grande movimento social, encabeçado pelas instituições de saúde, que visava à construção de um novo papel social para a mãe. A mulher passou a estabelecer com a criança uma relação íntima e de carinho, o que socialmente lhe conferiu o atributo representado por um "status maternal". Os cuidados maternais passaram a interferir na própria identidade feminina, fazendo as mulheres se reconhecerem e se legitimarem na função materna (Ariès, 1981; Badinter, 1985).

É na identificação com esse lugar social que os afetos das mães dão origem à idéia de amor materno, que vai se consolidar na França no final do séc. XIX e do séc. XX. Essa idéia encontra naturalização no conceito de "instinto materno", a partir do qual são construídas argumentações biológicas e científicas, próprias da modernidade, para justificar e modular os comportamentos de mães e filhos nesse novo século (Szapiro \& Féres-Carneiro, 2002).

No Brasil, autoras como Novelino (1989), Santos (1995) e Trindade e Enumo (2001) relatam que, principalmente no Nordeste, no séc. $X X$, a identidade feminina foi fortemente estruturada a partir da representação social da maternidade, na medida em que se atribuía à mulher a reprodução como principal função. As demais características femininas acabariam em segundo plano no seu reconhecimento social. Dessa forma, a maternidade não é apenas uma opção da mulher, mas a condição sine qua non para que ela constitua plenamente um ser natural.

Ancorada na noção de naturalidade e de atributos biológicos, a representação social da maternidade assume um caráter determinista. $\mathrm{O}$ fato de a mulher não desejar ser mãe e desempenhar o papel maternal é justificado por algum "problema", como, por exemplo, mecanismo de defesa (uma falsa vontade de não ser mãe), fruto de um impedimento orgânico para gerar filhos, conseqüência de algum "trauma" na infância que a impossibilita ter tal desejo ou ainda por uma deficiência de caráter (Santos, 1998; 
Trindade \& Enumo, 2001). Vale destacar, contudo, que a apropriação desse lugar simbólico socialmente construído se dá ao longo das várias relações sociais que os sujeitos estabelecem, nos diversos grupos sociais dos quais fazem parte.

\section{A representação social da maternidade no processo de socialização da criança}

Durante todo o seu processo de socialização (Berger \& Luckmann, 1973), em diferentes jogos interacionais, o sujeito, desde sua mais tenra infância, se apropria da realidade social em que vive, e, em conseqüência, das construções sociais acerca da maternidade.

Assim, pode-se compreender que, desde a infância, a criança se socializa, apropriandose do ideário do amor materno. No processo de socialização, constrói e reconstrói as diferenças de gênero, que se sustentam fortemente na diferenciação das funções do homem e da mulher no núcleo familiar.

A mãe, por assumir um papel privilegiado na constituição da identidade infantil, torna-se um modelo social do qual as crianças, desde cedo, precisam se apropriar e diferenciar para se constituírem enquanto sujeitos. Segundo Leontiev (1988) e Wallon (1945, 1971), as crianças, por ainda não desenvolverem na idade pré-escolar o pensamento abstrato, e buscando entender o mundo dos adultos, passam a imitar os diferentes papéis sociais, e, ao construir um modelo materno, podem se reconhecer como diferentes deste e assumir suas próprias identidades enquanto filhos. A esse processo de autodiferenciação do protótipo imitado, Wallon (1979) denomina sincretismo diferenciado, e afirma que "É querendo ser semelhante ao modelo que a criança se opõe à pessoa e que deve terminar por se distinguir também do modelo" ( $p$. 159). O imitar/brincar de mãe medeia, ainda, as interações sociais entre as crianças, que, nessa atividade, trocam, constroem e reconstroem significados da representação social da maternidade do grupo do qual fazem parte.

Da mesma forma que a brincadeira, os desenhos e as histórias infantis produzidas pela criança retratam suas construções simbólicas, permeadas pelas fantasias, que lhe permitem criar e dar significado à realidade que a cerca. Através dos jogos infantis, pode-se, assim, perceber como as crianças se apropriam e reconstroem as representações sociais da maternidade (Chombart e Feuerhahh, 1989).

\section{Marco teórico da pesquisa}

Para a realização deste estudo, partiu-se dos conceitos de representação social, propostos por Moscovici (1961, 1994), e de núcleo central, proposto por Abric (1994).

Jodelet (1984) define representação social como "uma forma de conhecimento socialmente elaborada e partilhada, tendo uma visão prática e concorrendo para a construção de uma realidade comum a um conjunto social" (p. 32). As representações sociais têm como objetivo a familiarização e a concretização de novos objetos sociais que estruturam a própria realidade a partir da atribuição de significados socialmente construídos (Sá, 1993).

A criança, quando nasce, se depara com um mundo novo e desconhecido, do qual precisa se apropriar durante o processo de socialização para se tornar parte integrante da sociedade e constituir um sujeito social, quando assume normas, valores, crenças, direitos e deveres, enfim, adquire uma identidade social (Doise, 1998; Duveen, 1994; Sá, 1996).

As representações sociais são construídas a partir de dois processos básicos: a objetivação e a ancoragem, que se desenvolvem 
simultaneamente. Na objetivação, cria-se uma imagem para o objeto, o núcleo figurativo, que não precisa necessariamente ser uma figura, mas um conjunto de significados que consiga concretizar o objeto. Nessa construção, há uma seleção aleatória de informações circulantes no imaginário social, a partir do consenso do grupo e de seus valores e de crenças anteriores. Essas informações sofrem uma descontextualização, o que estrutura um novo contexto que pode ou não ser coerente com seu contexto original (Sá, 1993).

Entrelaçada à objetivação, desenvolve-se a ancoragem, pela qual os conhecimentos prévios, as crenças e os valores servem de âncora, ou seja, de local de enraizamento dos novos conhecimentos que dão significação ao novo objeto social. Nesse processo, ocorrem: a) classificação do objeto social em determinadas categorias, em comparação com protótipos pré-existentes, e b) denominação do novo objeto, o que lhe garante identificação e unificação (Wagner, 1998).

Para o estudo das representações sociais, devem ser considerados aspectos de ordem social, individual, cognitiva e afetiva, além das práticas e comunicações sociais.

Na dimensão da afetividade, as relações que o grupo estabelece com o objeto social interferem diretamente na sua forma de concebê-lo, assim como os significados construídos acerca do objeto social interferem na sua relação afetiva com o grupo, isso porque as representações sociais dizem respeito à forma de os sujeitos sociais se relacionarem entre si e com o mundo, e, nessa dimensão, a afetividade não pode ser desconsiderada (Doise, 1998).

Ao se trabalhar com a representação social da maternidade em crianças, deve-se considerar que a mãe, na cultura atual, assume o lugar de principal agente formador da criança, mediadora de seu processo de socialização e, em conseqüência, da formação de sua identidade. Tal relevância do objeto social "mãe" para o cotidiano infantil torna imprescindível a função do afeto na construção da representação.

Com o objetivo de aprofundar o estudo de Serge Moscovici, Abric (1994) propôs a interpretação e a análise da estrutura das representações sociais, que considera serem organizadas a partir da formação de dois sistemas distintos, porém dependentes: o sistema central e o sistema periférico (Flament, 1989).

Tal proposta teórica surge como interpretação para as representações sociais que são, ao mesmo tempo, estáveis e móveis, rígidas e flexíveis, consensuais e marcadas por fortes diferenças individuais. Ao mesmo tempo em que são construídas pelo consenso de um determinado grupo, o que lhes oferece certa homogeneidade, rigidez e resistência a mudanças, elas também permitem a apropriação e a reconstrução individual, que lhes possibilitam o surgimento de novas características e lhes conferem conteúdos individuais (Wagner, 1998).

Na organização estrutural da representação, o núcleo central constitui o sistema organizador, uma vez que oferece o seu sentido essencial. Ele é formado por uma ou várias características mais importantes do objeto social, que, quando retiradas, modificam substancialmente a representação. Seus elementos são os mais consensuais e os mais fortemente arraigados no grupo, e oferecem estabilidade e rigidez à representação social (Flament, 1989; Wagner, 1998).

Em volta do sistema central, organizase o sistema periférico, que tem como principal função adequar o núcleo central às exigências do cotidiano. Os elementos periféricos moldam e justificam o núcleo central quando este é colocado em xeque pelas situações cotidianas e pelas diferenças individuais, oferecendo-lhe proteção e 
defesa. Para desenvolver tal função, esses elementos apresentam-se mais maleáveis e flexíveis e contemplam as diferenças individuais. Na medida em que justificam o núcleo central e se encontram mais relacionados às experiências dos sujeitos, eles se apresentam, ainda, como indicadores de comportamentos, já que modulam as práticas sociais a partir dos conteúdos centrais da representação (Wagner, 1998).

As representações sociais são constantemente reconstruídas a partir das práticas sociais. Dessa forma, torna-se relevante compreender como se tem estruturado a representação social da maternidade em determinados espaços sociais, com o propósito de identificar as mudanças no discurso que marcou o mito do amor materno e que orientou práticas e afetos de homens e mulheres.

A escolha pela investigação da representação social da maternidade em crianças se deve ao entendimento de que, nesse grupo social, podem ser evidenciadas as mais recentes estruturas simbólicas, perpassadas no processo de socialização. Para tanto, realizou-se este trabalho, cujo objetivo foi estudar o conteúdo e a estrutura da representação social da maternidade de crianças, com o propósito de contribuir com a discussão acerca das responsabilidades no cuidado com as crianças sob o olhar das desigualdades de gênero.

\section{Sujeitos e métodos}

Tomando como base tais considerações teóricas, investigou-se o conteúdo da representação social da maternidade compartilhada por crianças a partir de um estudo qualitativo, realizado no período de agosto a dezembro de 1998. Foram aplicadas entrevistas semidirigidas a uma amostra de 16 crianças de ambos os sexos, com idades entre 8 e 10 anos. Delimitou-se ainda que fossem crianças estudantes de uma escola particular da cidade do Recife, que, nas condições socio-econômicas brasileiras, caracteriza-se como um ambiente exclusivamente acessível às classes sociais média e alta. A escolha do ambiente escolar como delimitador da amostra justifica-se por especificar a quantidade e a qualidade de acesso às informações sociais, na medida em que agrupa sujeitos que compartilham representações ou "visões de mundo" semelhantes.

Valorizando a pluralidade metodológica que viabiliza maior obtenção de dados, solicitou-se às crianças, antes da entrevista semidirigida, a realização de um desenho referente à maternidade. A partir deste, as crianças eram estimuladas a contar uma história. Considerando a relevância dos jogos infantis para a construção e a apropriação das representações sociais, acredita-se que a utilização de desenhos e histórias possibilita, além de maior interação criança-pesquisadora, a abertura para seu mundo imaginário infantil, e, em conseqüência, para as representações sociais que compartilham.

Essa técnica teve como objetivo, ainda, servir de atrativo (Wallon, 1945) para as crianças pensarem a respeito da figura materna e, através do desenho, explicitarem imagens e significados ligados ao objeto, o que permitiu evidenciar o núcleo figurativo da representação (Abric, 1998). Todos os recursos metodológicos foram anteriormente testados em um grupo-piloto, o que possibilitou várias reformulações tanto em seu conteúdo quanto na forma de sua aplicação.

Para a análise dos dados coletados, realizouse o seguinte percurso: buscando evidenciar o conteúdo da representação social da maternidade, realizou-se a análise do relato das crianças, colhido tanto nas entrevistas quanto nas histórias. A interpretação dos significados e imagens explicitados nos desenhos serviu de complemento e respaldo para a análise do conteúdo realizada.

Para o estudo da estrutura da representação, utilizou-se o teste tri-hierarquizados 
sucessivos, proposto por Abric (Santos, 1996). Entretanto, a partir das especificidades do grupo trabalhado, foram necessárias algumas adaptações a fim de promover melhor aplicabilidade desse teste: pelo fato de se tratar de uma amostra composta por crianças, buscou-se evitar a exaustão das mesmas, e, dessa forma, em vez de 32, foram selecionados 16 termos que pareceram estruturadores dos relatos das crianças, para que elas os hierarquizassem conforme a relevância na definição do objeto social "mãe". A apresentação dos termos selecionados também foi adaptada em forma de cubos coloridos, em vez de fichas, o que proporcionou uma situação mais lúdica, tomando-se cautela para que os cubos não fossem de cores diferentes, o que poderia interferir na escolha da criança.

\section{Resultados e discussão}

Confrontando os dados analisados com o aparato teórico que sustenta este estudo, foi possível propor algumas interpretações acerca do conteúdo e da estrutura da representação social da maternidade compartilhada por essas crianças, representação essa que é estruturada a partir dos significados construídos pelos grupos sociais aos quais elas pertencem.

Antes da discussão acerca do conteúdo da representação estudada, deve-se ressaltar que não foram observadas diferenças qualitativas entre os discursos das meninas e dos meninos ou entre as diferentes idades, o que evidencia certa homogeneidade nos relatos do grupo.

A maternidade: O que é ser mãe?

Como era de se esperar, as crianças expressaram a representação da maternidade através do relato de seu cotidiano e de suas experiências concretas com a mãe.

A análise do conteúdo permitiu identificar que as crianças concebem a maternidade através da descrição de diversas características das mães. No conjunto das respostas, observou-se que o significado do ser mãe está demarcado pelos seguintes aspectos: características biológicas, características pessoais, trabalho exercido ou as atividades extradomésticas da mulher e a função materna. No entanto, ressalta-se que, para as crianças, as mães podem ser qualificadas a partir da sua competência na realização da função materna. Segundo Sá (1993), através das representações sociais, é atribuída uma posição ao objeto social em uma taxonomia que decorre de representações anteriores, o que caracteriza o processo de classificação dos objetos sociais. A representação tem, assim, a função de categorização social e de comparação social, que são fundamentais na formação da identidade social (Doise, 1998).

No caso em tela, a qualificação materna se expressou através de uma classificação hierárquica, na qual as mães podem ser consideradas "boas", "mais ou menos" e "ruins". As crianças não delimitaram um padrão de conduta para a definição de mãe, porém seus relatos apontam a construção de um modelo materno idealizado, no qual definem os tipos de mãe. Em seus relatos, as crianças se apóiam na idéia de que as "mães boas" amam os seus filhos. O amor da mãe e a dedicação ao filho, ao que resultou da análise, parecem ser o núcleo central (Abric, 1994) da representação da maternidade para as crianças estudadas. Nos relatos das entrevistas, observou-se também que a caracterização do amor materno se dava através do carinho, da compreensão e da dedicação, o que parece representar os elementos periféricos do núcleo central (Flament, 1989). Assim, a mulher que se afasta desse modelo ideal de mãe é considerada uma mãe ruim, e não uma "não mãe": Eu acho que tem mãe de todo jeito, só que eu acho que tem mãe que gosta do filho de jeito diferente (...) aquelas mães que são bem humoradas e outras que são mal (criança 1)".

No que se refere às características biológicas, as crianças ressaltam como única condição 
à maternidade o ser mulher, encontrando assim, nos atributos biológicos femininos, uma delimitação concreta da maternidade. As características biológicas justificam inclusive $\mathrm{o}$ bom desempenho da maternidade, uma vez que uma mãe é dedicada e ama o filho acima de todas as outras coisas, porque ela lhe deu à luz a ele. Outros argumentos biológicos expressados pelas crianças se referem ao fato de que a mãe deve ficar mais tempo com o filho porque é ela quem amamenta, ou consideram que a mãe se preocupa mais com o filho porque este é um pedaço dela.

Esses resultados permitem sugerir que a representação social da maternidade compartilhada pelo grupo de crianças estudadaséancorada (Sá, 1993) em parâmetros biológicos previamente estabelecidos, ou seja, a partir do processo de ancoragem, as crianças utilizam conhecimentos prévios, crenças e valores para dar significado e apropriar-se do objeto social. A ancoragem enfatiza que nenhuma construção se dá num vácuo, mas é a ...

...maneira na qual as informações novas são integradas e transformadas em um conjunto de conhecimentos socialmente estabelecidos e na rede de significações socialmente disponíveis (Jodelet, 1989, p. 47).

Observa-se, assim, que as crianças parecem reproduzir modelos do que é ser mulher, que são postos em debate pelo discurso feminista (Barbosa \& Lago, 1997; Szapiro \& Féres-Carneiro, 2002). Assim, as mulheres têm conquistado paulatinamente novos e significativos espaços de poder na sociedade e problematizado as divisões das tarefas familiares (Possatti \& Dias, 2002). Atualmente, já é possível encontrar novos arranjos familiares, em que os homens se co-responsabilizam pelos cuidados, até então prioritariamente femininos e maternos. Surgem, com isso, novos modelos de paternidade, que oferecem novos elementos simbólicos para a representação da maternidade (Medrado, 1999). Esses movimentos, no entanto, são muito recentes, e não parecem ainda ter atingido o núcleo central da representação da maternidade, fato esse que parece justificar o discurso de que tais homens estariam desempenhando atividades maternas, e não paternas.

Ainda no campo das discussões sobre as relações de gênero, observa-se que a representação social da maternidade ora estudada também parece buscar outros referenciais simbólicos que marcam o gênero feminino para a definição do que é ser mãe. Assim, das entrevistas, emergiram respostas, mesmo que em menor intensidade, referentes aos aspectos pessoais, ao trabalho e às atividades extra domésticas.

Uma parte das crianças descreveu as mães como mulheres bonitas, simpáticas e caridosas, o que parece evidenciar categorias de padrões de comportamento socialmente atribuídas à mulher. Ao mesmo tempo, as condutas e a inserção social da mulher parecem estar relacionadas ao bom desempenho da maternidade, uma vez que o conjunto de descrições indica que a boa mãe é uma mulher educada, simpática, amiga, sensível, casada, que não consome bebida alcoólica e não fuma.

Pode ser evidenciado, então, que, na definição das boas condutas sociais e do modelo hegemônico da constituição familiar, estão presentes, de forma significativa, referenciais burgueses, com o reforço da monogamia, da heterossexualidade e da família nuclear (pai-mãe-filho) (Elias, 1994; Folle \& Geib, 2004).

Buscando delimitar de forma mais específica, então, o que caberia à mãe realizar no exercício da maternagem, investigou-se no que consistiria, para as crianças, a função materna. Em suas narrativas, as crianças descrevem um modelo ideal de mãe, admitindo padrões reais de condutas maternas diferentes. Das respostas das crianças, emergiram, principalmente, como 
Buscando delimitar de forma mais específica, então, o que caberia à mãe realizar no exercício da maternagem, investigou-se no que consistiria, para as crianças, a função materna. funções maternas, a educação e a imposição de limites bem como a oferta de lazer e os cuidados básicos com os filhos.

Ao descreverem as funções maternas, a maioria das crianças tende a aproximar as funções de suas mães ao conceito da mãe ideal. Elas relataram que são educadas a partir da imposição de limites e normas: “...se ele (o filho) quiser ir tomar banho de chuva, ela (a mãe ruim) deixa, se quiser tomar banho de piscina até tarde, ela (a mãe ruim) deixa, e a mãe boa não deixa (criança 5)".

As crianças revelam ainda que a imposição de limites deve ser preferencialmente realizada a partir do diálogo. No entanto, admitem a possibilidade de castigos, inclusive físicos, quando têm condutas inadequadas. Para as crianças, as mães devem procurar entender e perdoar os filhos, saber diferenciar comportamentos infantis de comportamentos inadequados e serem justas ao castigar.

No que se refere ao lazer, foi notável como as crianças relataram de forma mais entusiasmada a sua relação com a mãe. As crianças revelaram satisfação ao dizer que suas mães thes compram presentes, dão objetos, dinheiro e brinquedos. Ao que parece, para as crianças, tais comportamentos são considerados expressão do amor materno, podendo, ainda, a mãe deixar de oferecêlos como uma forma correta de punição. Observa-se, nesse ponto, o poder dos valores capitalistas e do culto ao consumo como norteadores das relações afetivas entre mães e filhos.

Em relação aos cuidados básicos com as crianças, foram citados os cuidados com higiene, alimentação e sono. Entretanto, foi notável, nos relatos das crianças, o fato de que suas mães não aparecem diretamente envolvidas com tais cuidados. As crianças relataram que suas mães determinam que elas façam tarefas como cuidar da higiene do corpo, comer, trocar de roupa ou dormir. Assim, essas descrições parecem estar mais relacionadas à função de dar limites do que propriamente de proporcionar cuidados básicos.
Ao que parece, o desempenho, de fato, dos cuidados básicos, ou seja, dar banho, alimentar, vestir e pôr a criança para dormir está relacionado à trabalhadora doméstica. A presença dessa personagem no ambiente familiar é tão expressiva para as crianças entrevistadas que, ao descreverem com quem moravam, elas a incluíam no conjunto dos atores familiares. Às mães são atribuídas as funções de dar carinho, diálogo, brinquedos, educação - tanto escolar, quanto moral - etc. Esse resultado pode sugerir a influência das condições socioeconômicas na formação da representação social sobre a maternidade na medida em que, nesse grupo social, os cuidados básicos já estão assegurados por uma outra mulher, e, assim, para essas crianças, o cuidar parece não fazer parte da função materna.

Tais resultados são bastante contrastantes daqueles encontrados por Santos (1995) em trabalhos sobre a representação social da maternidade com crianças de classes menos favorecidas, que relacionam diretamente a função materna ao oferecimento dos cuidados básicos. No cenário familiar dessas crianças, não há uma empregada doméstica, e os cuidados básicos são responsabilidade exclusiva das mães. Ao mesmo tempo, as dificuldades financeiras em que essas crianças se encontram tornam incerta a própria existência de tais cuidados. Nesse contexto, há maior valorização dos cuidados básicos, já que estes não ocorrem de forma certa e natural.

Por outro lado, Santos (1995) e Folle e Geib (2004) salientam que as mães de classe social mais alta, por terem mais acesso ao discurso psicologizante, passam a demonstrar seu amor através do carinho, diálogo, lazer, etc. Tais aspectos evidenciam que a representação social da maternidade apresenta elementos diferentes de acordo com as diferentes camadas sociais.

Núcleo central e elementos periféricos

Finalmente, a partir das interpretações do conteúdo da representação social da 
maternidade das crianças estudadas, foi aplicado o teste de tri-hierarquização dos itens (Abric, 1994), tendo sido verificados os elementos constituintes do núcleo central e a hierarquização de alguns dos elementos periféricos.

Para as crianças, o conceito de mãe está intimamente ligado à idéia de dedicação. A principal função da mãe está relacionada à sua abnegação e providência como resultado do amor materno incondicional: "Se ele (o filho) for desobediente, qualquer coisa, tem que gostar do mesmo jeito" (criança 2).

A partir dos parâmetros de mãe boa e mãe ruim, as crianças avaliam suas próprias mães, e, nessa comparação, percebe-se a tentativa de aproximação das suas mães à mãe ideal: "Tem vários tipos de mãe. Um deles é a boa, né? Por exemplo, minha mãe sempre foi superlegal comigo, sempre me deu carinho e me apoiou na hora que eu precisava" (criança 5).

Entretanto, as mães não são consideradas exemplos fiéis do modelo idealizado. Elas são percebidas com qualidades e defeitos, podendo ser mais ou menos "boas mães".

Ao que parece, o núcleo central se estrutura em dois significados sobre a maternidade e que dão sentido a toda a representação. Para as crianças, o amor materno e a dedicação exclusiva ao filho são as características mais importantes de uma boa mãe. Esse referencial é o que parece servir como melhor descrição e delimitação da maternidade, já que, segundo Abric (1994), é o núcleo central que fornece o sentido último da representação. $\mathrm{O}$ que define o caráter central de um elemento é a sua dimensão qualitativa, uma vez que sua centralidade não é garantida por sua freqüência, mas sim, por sua significação na representação (Sá, 1996).

Ao mesmo tempo, esses dois elementos centrais (amor e abnegação) encontram-se entrelaçados e se justificam mutuamente, na medida em que a mãe se dedica plenamente ao filho por amá-lo acima de todas as outras coisas. Ao mesmo tempo, a dedicação materna é a forma mais explícita de demonstração de seu amor. Juntos, o amor e a abnegação servem de suporte para todas as outras construções simbólicas acerca da maternidade.

Compreende-se, assim, a função geradora do núcleo central, pois, a partir dele, são construídos e transformados o sentido e o valor dos demais elementos da representação. Além desta, percebe-se a função organizadora do núcleo central ao determinar as relações estabelecidas entre os elementos, o que oferece unidade e estabilidade à representação (Sá, 1996).

Articulados ao núcleo central, encontram-se os elementos periféricos da representação social. Os elementos periféricos mais significativos desse caso estudado encontramse numa ordem hierárquica, segundo sua proximidade com o núcleo central e a conseqüente relevância na estruturação da representação.

Em maior centralidade, encontra-se a idéia de que a mãe é carinhosa com o filho. Deve-se, contudo, salientar que carinho e amor, para as crianças, não são sinônimos, pois a mãe pode amar e não ser carinhosa com o filho. Perifericamente ao carinho, aparecem, na mesma ordem hierárquica, os significados de que a mãe é compreensiva e entende as ações e os sentimentos do filho, ensina-o, orienta-o e leva-o à escola. Finalmente, numa posição mais afastada do núcleo central, está a idéia de que a mãe leva o filho para passear.

Compreende-se, assim, que a representação social da maternidade compartilhada pelas crianças se estrutura na idéia de amor e dedicação, significados que justificam as demais características maternas, dentre as quais têm maior relevância a afetuosidade, a compreensão, a educação e o lazer.

Percebe-se, assim, que as representações sociais ilustram o modus operandi de um determinado grupo social. Moscovici (1961) salienta que as representações 
sociais funcionam como reguladoras das comunicações e dos comportamentos dos sujeitos, e Abric (1994) acrescenta a estas as funções identitária e justificadora de condutas. Tais atributos das representações sociais permitem compreender que a forma como tais crianças constroem coletivamente o que é ser mãe estabelece dentro do grupo social padrões de comportamentos que regularão modelos de identificação para os futuros jovens e adultos.

\section{Considerações finais}

Os resultados ora apresentados podem servir de suporte para a compreensão da construção social da maternidade em um determinado grupo social, e refletem anos de construções simbólicas que dão sentido e orientam as práticas sociais e os afetos dos sujeitos.

A consideração de tais resultados permite não apenas reconhecer uma realidade como também adquirir subsídios para, no campo ético, avaliá-la e intervir sobre a mesma. A partir do que foi discutido no presente estudo, é necessário o debate acerca de questões que parecem cruciais. Devem ser consideradas as desigualdades de gênero que insistem em se reinscrever nas produções sociais e que marcam as formas de homens e mulheres se relacionarem. É preciso compreender até que ponto a função da maternidade estrutura a identidade feminina e quais as repercussões daí advindas no desenho de novos arranjos familiares e na inserção da figura paterna de forma mais pró-ativa frente aos cuidados com a casa e com os filhos. Compreender os percursos que os modelos e padrões de comportamento e relações sociais fazem ao longo dos anos deverá servir de instrumento para o enfrentamento das desigualdades de gênero e para a proposição de novas modalidades de relações sociais. Por fim, é preciso reconhecer o papel da criança como sujeito ativo e construtor de representações sociais assim como sua significativa relevância para a manutenção ou reconstrução de valores mais comprometidos ética e politicamente e de relações afetivas mais satisfatórias.

\section{Juliana Sampaio}

Psicóloga, Doutora em Saúde Coletiva.

E-mail: julianasmp@hotmail.com

\section{Maria de Fátima de Souza Santos}

Psicóloga, Doutora em Psicologia pela Universidade de Toulouse II; Professora associada 1 da Universidade Federal de Pernambuco (UFPE).

E-mail: mfsantos@ufpe.br

\section{Maria Rejane Ferreira da Silva}

Enfermeira, Doutora em Saúde Pública.

Departamento de Saúde Pública - Fundação Oswaldo Cruz - Campus da Universidade Federal de Pernambuco (UFPE).

E-mail: rejane@cpqam.fiocruz.br

Endereço para correspondência:

Avenida Cardoso de Sá, no 85, ap. 1401, Centro Cep: 56302-110, Petrolina-PE

Recebido 24/04/07 Reformulado 24/09/07 Aprovado 19/11/07 


\section{Referências}

Abric, J. C. (1994). L'organisation interne des représentations sociales: Système central et système péripherique. In C. Guimelli, (Ed.), Structures et transformations des représentations sociales (pp. 73-84). Neuchâtel/Paris: Delachaux et Niestlé.

Abric, J. C. (1998). A abordagem estrutural das representações sociais. In A. S. Moreira , \& D. C.Oliveira (Eds.), Estudos interdisciplinares de representação social. (pp. 27-38). Goiana: AB.

Ariès, P. (1981). História social da criança e da família. (2a ed.) Rio de Janeiro: LTC.

Azevedo, K. R., \& Arrais, E. R. (2006). O mito da mãe exclusiva e seu impacto na depressão pós-parto. Psicologia: Reflexão e Crítica, Porto Alegre, 19(2), 269-276.

Badinter, E. (1985). Um amor construído. O mito do amor materno. Rio de Janeiro: Nova Fronteira.

Barbosa, R. M., \& Lago, T. G. (1997). Aids e os direitos reprodutivos: para além da transmissão vertical. In $R$. Parker,(Ed.), Políticas, instituições e Aids (pp. 163-176). Rio de Janeiro: Zahar/ABIA.

Berger, P., \&, Luckmann, T. (1973). A construção social da realidade. Rio de Janeiro: Vozes.

Chombart, L., \&, Feuerhahh, N. (1989). La représentation sociale dans le domaine de l'enfance. In D. Jodelet, Les représentations sociales (pp. 320-340). Paris: PUF.

Dias, A. C. \&, Lopes, R. C. S. (2003). Representações da maternidade de mães jovens e suas mães. Psicologia em Estudo, Maringá, 8 (no esp.), 63-73.

Doise, W. (1998). Représentation sociale dans l'identité personnelle. Trabalho apresentado na Jornada Internacional sobre Representações Sociais, Natal.

Duveen, G. (1994). Crianças enquanto atores sociais: as representações sociais em desenvolvimento. In S. Jovchelovitch, \& Guareschi, P. (Eds.), Textos em representação social. (pp.261296). Petrópolis: Vozes.

Elias, N. (1994). O processo civilizador. Uma história dos costumes. Rio de Janeiro RJ: Zahar.

Flament, C. (1989). Structure et dynamique des représentations sociales. In D. Jodelet, Les représentations sociales (pp. 204219). Paris: PUF.

Folle, E., \& Geib, L. T. C. (2004). Representações sociais das primíparas adolescentes sobre o cuidado materno ao recémnascido. Revista Latino-Americana de Enfermagem, São Paulo, 12(2), 183-190.

Jodelet, D. (1984). La representación social: fenómenos, concepto y teoria. (pp. 469-494). In S. Moscovici, (Ed.), Psychologie sociale. Paris: PUF.

Jodelet, D. (1989). Les représentations sociales. Paris: PUF.

Leontiev, A. N. (1988). Uma contribuição à teoria do desenvolvimento da psique infantil. In L. Vigotsky, (Ed.), Linguagem, desenvolvimento e aprendizagem. (pp. 59-83). São Paulo: Ícone-EDUSP
Medrado, B., \& Lyra, J. (1999). A adolescência "desprevenida" e a paternidade na adolescência: uma abordagem geracional e de gênero. In Brasil. Ministério da Saúde. Secretaria de Políticas de Saúde. Área de Saúde do Adolescente e do Jovem. Cadernos, Juventude, Saúde e Desenvolvimento, Brasília, 1.

Moscovici, S. (1961). La psychanalyse, son image et son public: Étude sur la représentation sociale de la psychanalyse. Paris: PUF.

Moscovici, S. (1994). A melhor maneira de se provar o pudim ainda é comê-lo. Texto apresentado na 2 a Conferência Internacional sobre Representações Sociais, Rio de Janeiro.

Novelino, A. M. (1989). A cartilha da mãe perfeita: um discurso normatizador da psicologia de mídia. Dissertação de Mestrado, de Psicologia. Pontifícia Universidade Católica de São Paulo, São Paulo.

Possatti, I. C., \& Dias, M. R. (2002). Multiplicidade de papéis da mulher e seus efeitos para o bem-estar psicológico. Psicologia: Reflexão e Crítica, Porto Alegre, 15(2), 293-301.

Sá, P. C. (1993). Representações sociais: o conceito e o estado da teoria. In M. J. Spink, (Ed.), O conhecimento no cotidiano - as representações sociais na perspectiva da Psicologia social. (pp. 19-44). São Paulo: Brasiliense.

Sá, P. C. (1996). O núcleo central das representações sociais. Petrópolis RJ: Vozes.

Santos, M. F. S. (1995). Representação social da maternidade: o novo sob uma nova roupagem? UFPE. Não publicado.

Santos, M. F. S. (1996). Questões metodológicas em representação social. Curso de Mestrado em Representação Social, UFES.

Santos, M. F. S. (1998). Representação social e identidade. In A. S. Moreira, \& D.C. Oliveira (Eds.), Estudos interdisciplinares de representação social. (pp. 151-159). Goiana: AB.

Szapiro, E. M., \& Féres-Carneiro, T. (2002). Construções do feminino pós anos sessenta: o caso da maternidade como produção independente. Psicologia: Reflexão e Crítica, Porto Alegre, 15(2), 179-188.

Trindade, Z. A., \& Enumo, S. R. F. (2001). Representações sociais de infertilidade feminina entre mulheres casadas e solteiras. Psicologia, Saúde e Doenças, Lisboa, 2( 2), 5-26.

Wagner, W. (1998). Sociogênese e características das representações sociais. In A. S. Moreira, \& Oliveira, D.C. (Eds.), Estudos interdisciplinares de representação social. (pp.325). Goiana: AB

Wallon, H. (1945). Imitation et représentation. In De l'Acte à la Pensée. (E. S. Lima, trad.). Paris: Flammarion.

Wallon, H. (1971). As origens do caráter na criança - os prelúdios do sentimento de personalidade. São Paulo: Difusão Européia do Livro.

Wallon, H. (1979). Do acto ao pensamento: ensaio de psicologia comparada. Lisboa: Moraes. 